\title{
Aortic arch reconstruction in the Norwood operation: It is more than just geometry
}

\author{
Harold M. Burkhart, MD, ${ }^{\mathrm{a}}$ Jess L. Thompson, MD, ${ }^{\mathrm{a}}$ and Arshid Mir, $\mathrm{MD}^{\mathrm{b}}$
}

\footnotetext{
From the ${ }^{\mathrm{a}}$ Division of Cardiovascular and Thoracic Surgery and ${ }^{\mathrm{b}}$ Section of Pediatric Cardiology, University of Oklahoma Health Sciences Center, Oklahoma City, Okla.

Disclosures: Authors have nothing to disclose with regard to commercial support.

Received for publication Oct 14, 2018; accepted for publication Oct 15, 2018; available ahead of print Nov 22, 2018.

Address for reprints: Harold M. Burkhart, MD, Division of Cardiovascular and Thoracic Surgery, University of Oklahoma Health Sciences Center, PO Box 26901 WP-2230, Oklahoma City, OK 73105 (E-mail: Harold-burkhart@ouhsc.edu).

J Thorac Cardiovasc Surg 2019;157:708-9

$0022-5223 / \$ 36.00$

Copyright $($ c 2018 by The American Association for Thoracic Surgery

https://doi.org/10.1016/j.jtcvs.2018.10.079
}

Much attention has been given to the reconstructed aortic arch anatomy in the Norwood operation with regard to hypoplastic left heart syndrome (HLHS) outcomes. Having the arch too big, leaving or residual obstruction or having it develop, and using patch material have all been implicated in poor results after the Norwood procedure. Knowing that the right ventricle may struggle as the systemic ventricle long-term, more data are being sought with regard to the abnormal afterload imposed on the right ventricle by a reconstructed aortic arch.

In this issue of the Journal, Schäfer and colleagues ${ }^{1}$ used magnetic resonance imaging to compare the biomechanical properties of the aorta in 37 patients with a single ventricle (19 with HLHS; 14 with tricuspid atresia, 2 of which required aortic arch reconstruction; and 4 with pulmonary atresia) to the aortas of 18 control subjects with a 2 -ventricle heart. Data describing the biomechanical properties of the aorta were obtained by phase-contrast magnetic resonance imaging with pulse-wave velocity (PWV) and relative area change. The average age of the patients with singleventricle anatomy when the magnetic resonance imaging was performed was 11 years, and that of the control patients was 10 years. Schäfer and colleagues ${ }^{1}$ found that loss of elasticity of the ascending aorta was elevated the greatest in patients with HLHS but that all patients with singleventricle anatomy had stiffer aortas than did the control subjects. Importantly, stiffness indices measured in the ascending aorta were associated with worsened ventricular function and ventriculoaortic coupling. Of note, descending aorta stiffness indices were the same in all groups.

The significance of the article is highlighted in its discussion section. First, the biomechanical function of the reconstructed ascending aorta in patients with HLHS is severely affected. Second, this abnormal ascending aorta has increased stiffness that contributes to right ventricular afterload. Finally, ventriculoaortic coupling is adversely altered. Others have reported findings similar to these,

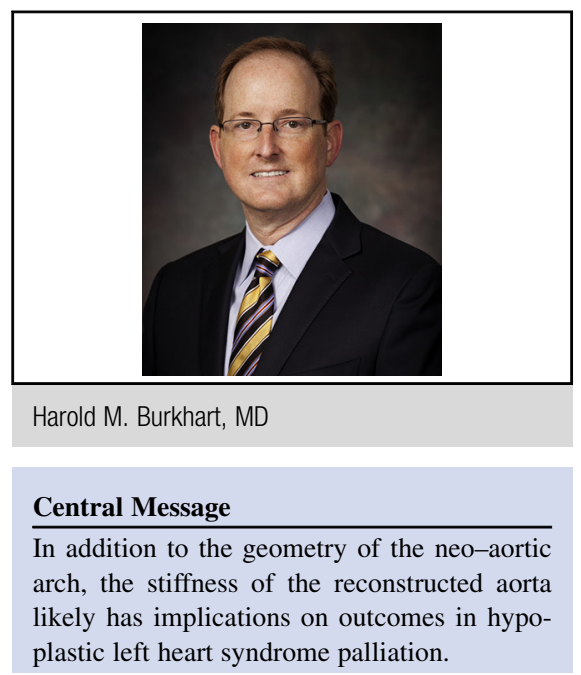

See Article page 699 showing increased PWV and decreased distensibility in the ascending neoaorta with normal properties in the descending aorta. $^{2-4}$

There are a few limitations to the study. The first, which Schäfer and colleagues ${ }^{1}$ acknowledge, is the lack of crosssectional imaging of the aortic arch and blood pressure measurements throughout the scan. This information could further delineate the segments of the reconstructed aorta most severely impaired with regard to biomechanical properties. In addition, specific information such as the size of the native aorta and the amount of patch needed in the aortic arch reconstruction could be helpful in delineating the cause of increased stiffness-whether it is due to the patch, to multiple suture lines, to abnormal native intrinsic aortic wall properties, or to fibrosis development. Finally, Schäfer and colleagues ${ }^{1}$ state that there are increased end-diastolic and end-systolic volumes in these patients; however, apart from elevated PWV, tricuspid and neoaortic valvular regurgitation as well as collateral flow can account for these abnormal values. Reporting these data obtained from other imaging modalities would have been helpful.

In summary, the reconstructed neoaorta in patients with HLHS who have undergone the Norwood procedure appears to have increased PWV with decreased distensibility. In a Fontan system relying on a single systemic right ventricle, where mild derangements can have substantial 
effects on long-term outcomes, these depressed biomechanical properties likely play a significant role. As we define the perfect aortic arch reconstruction, in addition to geometry, factors such as patch material, patch size, aortic arch size, and effective postoperative afterload management will have to be included.

\section{References}

1. Schäfer M, Younoszai A, Truong U, Browne LP, Mitchell MB, Jaggers J, et al. Influence of aortic stiffness on ventricular function in patients with Fontan circulation. J Thorac Cardiovasc Surg. 2019;157:659-707.
2. Voges I, Jerosch-Herold M, Hedderich J, Westphal C, Hart C, Helle M, et al. Maladaptive aortic properties in children after palliation of hypoplastic left heart syndrome assessed by cardiovascular magnetic resonance imaging. Circulation. 2010;122:1068-76.

3. Biglino G, Schievano S, Steeden JA, Ntsinjana H, Baker C, Khambadkone S, et al; Modeling of Congenital Hearts Alliance (MOCHA) Collaborative Group. Reduced ascending aorta distensibility relates to adverse ventricular mechanics in patients with hypoplastic left heart syndrome: noninvasive study using wave intensity analysis. J Thorac Cardiovasc Surg. 2012;144:1307-13.

4. Fogel MA, Li C, Nicolson SC, Spray TL, Gaynor JW, Fuller S, et al. Comparison by magnetic resonance phase contrast imaging of pulse-wave velocity in patients with single ventricle who have reconstructed aortas versus those without. Am J Cardiol. 2014;114:1902-7. 